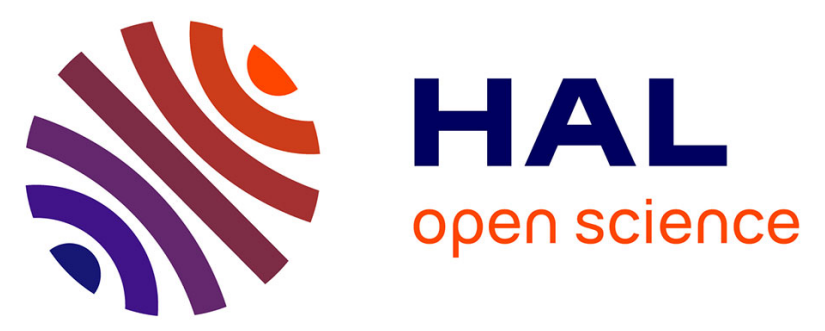

\title{
IgG1 Subclass Restriction and Biochemical Peculiarities of Monoclonal Immunoglobulins in Scleromyxedema
}

Tania Petersen, Thibault Mahévas, Pauline Cannet, Jean-David Bouaziz, Camille Hua, Charles Zarnitsky, Philippe Modiano, François Lifermann, Bruno Sassolas, Olivier Carpentier, et al.

\section{To cite this version:}

Tania Petersen, Thibault Mahévas, Pauline Cannet, Jean-David Bouaziz, Camille Hua, et al.. IgG1 Subclass Restriction and Biochemical Peculiarities of Monoclonal Immunoglobulins in Scleromyxedema. Clinical Laboratory, 2021, 67 (03), Online ahead of print. 10.7754/Clin.Lab.2020.200605 . inserm-03175493

\section{HAL Id: inserm-03175493 https://www.hal.inserm.fr/inserm-03175493}

Submitted on 20 Mar 2021

HAL is a multi-disciplinary open access archive for the deposit and dissemination of scientific research documents, whether they are published or not. The documents may come from teaching and research institutions in France or abroad, or from public or private research centers.
L'archive ouverte pluridisciplinaire HAL, est destinée au dépôt et à la diffusion de documents scientifiques de niveau recherche, publiés ou non, émanant des établissements d'enseignement et de recherche français ou étrangers, des laboratoires publics ou privés. 


\section{IgG1 Subclass Restriction and Biochemical Peculiarities of Monoclonal Immunoglobulins in Scleromyxedema}

Tania Petersen ${ }^{1,2}$, Thibault Mahévas ${ }^{3}$, Pauline Cannet ${ }^{1,2}$, Jean-David Bouaziz ${ }^{4}$, Camille Hua ${ }^{5}$, Charles Zarnitsky ${ }^{6}$, Philippe Modiano ${ }^{7}$, François Lifermann ${ }^{8}$, Bruno Sassolas ${ }^{9}$, Olivier Carpentier $^{10}$, Arsène Mékinian ${ }^{3}$, Laurent Garderet ${ }^{11}$, Pierre Aucouturier* ${ }^{* 1,2}$, Yannick Chantran*1,2

${ }^{1}$ Département d'Immunologie Biologique, Hôpital St-Antoine, Assistance Publique-Hôpitaux de Paris, France

${ }^{2}$ Sorbonne Université / Inserm UMRS 938, Hôpital St-Antoine, Paris, France

${ }^{3}$ Service de Médecine Interne, Hôpital St-Antoine, Assistance Publique-Hôpitaux de Paris, France

${ }^{4}$ Service de Dermatologie, Hôpital Saint-Louis, Université de Paris, Assistance PubliqueHôpitaux de Paris, France

${ }^{5}$ Service de Dermatologie, Hôpital Henri Mondor, Assistance Publique-Hôpitaux de Paris / Université Paris Est Créteil, EpiDermE (EA7379), Créteil, France

${ }^{6}$ Service de Rhumatologie, Groupe Hospitalier du Havre, Hôpital Jacques Monod, Le Havre, France

${ }^{7}$ Service de Dermatologie, Hôpital Saint Vincent de Paul, Université Catholique de Lille, Lille, France

${ }^{8}$ Service de Médecine Interne, Centre Hospitalier de Dax, Dax, France

${ }^{9}$ Département de Médecine Vasculaire, Médecine Interne et Pneumologie, Centre Hospitalier Universitaire (CHU) de Brest, Hôpital La Cavale Blanche, Brest, France ${ }^{10}$ Service de Médecine Interne, Centre Hospitalier Victor Provo, Roubaix, France

${ }^{11}$ Service d'Hématologie Clinique, Hôpital Pitié-Salpétrière, Assistance Publique-Hôpitaux de Paris, France

$*$ Equal contribution

Corresponding Author:

Pierre Aucouturier 
UMRS 938, Kourilsky building

184 rue du faubourg St-Antoine

F-7012, Paris, France

Tel: + 33149284678

Email: pierre.aucouturier@inserm.fr

Source of Funds: This work was supported by Assistance Publique - Hôpitaux de Paris (APHP) and Sorbonne Université (Paris, France)

Declaration of Interest: none

Running Title: Monoclonal IgG1 in scleromyxedema

SUMMARY

Background: Scleromyxedema (SME) is a rare mucinosis associated with monoclonal gammopathy. Several biochemical peculiarities of monoclonal immunoglobulins (Ig) in SME patients were reported in case reports or short series, such as $\operatorname{IgG} \lambda$ over-representation, cationic migration, and partial deletion.

Methods: Monoclonal immunoglobulins (Ig) from the serum of 12 consecutive patients diagnosed with scleromyxedema (SME) were analyzed using electrophoretic and immunoblotting techniques.

Results: All monoclonal Ig from 12 SME were of IgG1 subclass, with an overrepresentation of the lambda-type light chain and a cationic mobility on standard zone electrophoresis, as compared with 21 cases of monoclonal gammopathy of undetermined significance (MGUS) of IgG1 subclass. Reactivity with specific monoclonal antibodies demonstrated no evident deletion of the heavy chain constant domains, which was also confirmed by analysis of Ig heavy chain molecular weight on a purified monoclonal component from one case.

Conclusions: Significant isotype restriction of both heavy and light chains, and peculiar biochemical properties suggest that monoclonal Ig might be involved in pathophysiological events of SME.

Keywords: scleromyxedema, monoclonal gammopathy, immunoglobulin, IgG subclass 
Abbreviations: MGUS: monoclonal gammopathy of undetermined significance, SDS-PAGE: sodium dodecyl sulfate-polyacrylamide gel electrophoresis, SME: scleromyxedema

\section{INTRODUCTION}

Scleromyxedema (SME) is a rare systemic mucinosis associated with a monoclonal gammopathy $(\mathrm{MG})$ that belongs to the recently described group of Monoclonal Gammopathy of Cutaneous Significance (MGCS) [1]. It is characterized by a histological triad including intense dermal mucin deposition, increased fibroblast proliferation, and fibrosis, and is responsible for a scleroderma-like syndrome associated with generalized papular eruption [2]. Various systemic manifestations are common in SME, including cutaneous, neurological, and articular involvements. Dermato-neuro-syndrome (DNS), an acute encephalopathy leading to seizure, coma, and death, is the most severe complication of the disease. Despite the rare association of SME with hematologic malignancy (10 - 15\%) [3], mortality remains high among reported SME cases [2,3].

The almost constant occurrence of MG in SME has made it a diagnostic criterion along with cutaneous eruption, the histological triad on skin biopsy, and the absence of a thyroid dysfunction $[2,4]$. However, a direct or indirect role of the monoclonal immunoglobulin $(\mathrm{Ig})$ in SME pathogenesis remains uncertain. Treatments aimed at eradicating a monoclonal plasma cell proliferation proved efficient in certain cases $[3,5,6]$.

Intrinsic biochemical peculiarities of monoclonal Ig in SME patients were reported. A cationic migration and $\operatorname{IgG} \lambda$ restriction was found in 5 cases [7]. In 1978, Kitamura et al. [8] found a low molecular weight $(110 \mathrm{kDa})$ monoclonal $\mathrm{IgG}$, suggesting deletion of a part of the Fd fragment, in a single case of SME. Subsequent studies showed that the monoclonal component is always of the $\operatorname{IgG}$ class with an over-representation of the lambda-type light chain $[2,3]$.

Here, we identified the IgG subclass and light chain type of the monoclonal component in 12 SME cases, and assessed their biochemical peculiarities, including mobility on zone electrophoresis and presence of constant domains of heavy-chains.

\section{MATERIALS AND METHODS}

\section{Patients}

Serum samples were collected from 12 consecutive patients diagnosed with SME, recruited from 9 French centers between June 2017 and November 2018 by MINHEMON French network (dysimmune disorders associated to hemopathies and cancers). Samples were kept at 
$-20^{\circ} \mathrm{C}$ until analyses. As a control group for electrophoretic migration, 39 sera from consecutive patients with MGUS were collected at the Saint Antoine hospital (Paris). All analyses, including electrophoresis and immunochemical studies, were part of the routine biological follow-up of patients.

\section{Characterization of isotypes and electrophoretic mobility of serum monoclonal Ig}

Serum monoclonal Ig were identified by standard immunofixation (Sebia, France). Electrophoretic mobilities of monoclonal $\mathrm{IgG}$ were determined by measuring their retention factor (Rf) relative to albumin. Then, relative mobilities of monoclonal IgG were normalized against the Rf of a single serum IgG (SME patient \#7) serving as an internal standard.

\section{Characterization of IgG subclasses and presence of heavy chain constant domains}

Monoclonal IgG subclass typing and reactivities for heavy chain constant domains $\mathrm{CH} 1$, $\mathrm{CH} 2$, and $\mathrm{CH} 3$ were performed using a home-made immunoblotting method [9]: appropriate dilutions of serum samples were submitted to thin-layer agarose gel zone electrophoresis and transferred by single pressure $\left(15 \mathrm{~g} / \mathrm{cm}^{2}\right.$ for 10 minutes) onto a $0.2 \mu \mathrm{m}$ nitrocellulose membrane. The membrane was then blocked for 30 minutes in 5\% skimmed milk in phosphate buffered saline $\mathrm{pH} 7.4$ (PBS) and cut into strips that were incubated for 60 minutes at room temperature with appropriate primary mouse monoclonal antibodies diluted in $0.05 \%$ Tween-20, 0.02\% bovine serum albumin PBS. The monoclonal antibodies were specific for kappa and lambda light chains, and $\mathrm{IgG} 1, \mathrm{IgG} 2, \mathrm{IgG} 3$, and $\mathrm{IgG} 4$ heavy chain isotypes (clones HP6053, HP6054, NL16, GOM2, ZG4, and RJ4, respectively) and for IgG constant domains (anti-CH1: TM15, ZB8, HP6044; anti-CH2: G7C, HP6018; anti-CH3: X3A8, HP6017). After washing with $0.05 \%$ tween-PBS at $4^{\circ} \mathrm{C}$, strips of nitrocellulose membrane were incubated with alkaline phosphatase-conjugated rabbit polyclonal anti-mouse $\operatorname{IgG}$ diluted in $0.05 \%$ tween-20, 0.02\% BSA/PBS. Strips were washed as before, and revealed by chromogenic reaction with tetrazolium nitroblue / bromo-chloro-indolyl phosphate in $0.1 \mathrm{M} \mathrm{NaCl} 0.1 \mathrm{M}$ $\mathrm{MgCl} 20.1 \mathrm{M}$ TRIS/HCl buffer $\mathrm{pH} 9.5$.

\section{Purification of monoclonal Ig and heavy and light chain molecular weight determination}

The monoclonal IgG could be purified from the serum of one SME case and from a control IgG1 myeloma patient, using ion exchange chromatography. Serum samples were fractionated on a diethylaminoethyl (DEAE)-Trisacryl column in $10 \mathrm{mM}$ TRIS/HCl buffer $\mathrm{pH}$ 7.8 with a 0 to $0.1 \mathrm{M} \mathrm{NaCl}$ linear gradient. Protein fractions were concentrated by ultrafiltration and purity was assessed by standard thin layer agarose zone electrophoresis at $\mathrm{pH}$ 8.6. Purified (> 95\%) fractions were reduced with $10 \mathrm{mM}$ dithiothreitol in $1 \%$ sodium 
dodecyl sulfate (SDS) loading buffer at $95^{\circ} \mathrm{C}$ for 3 minutes, and $1 \mu \mathrm{g}$ protein of each was fractionated by $12 \%$ SDS polyacrylamide gel electrophoresis (SDS-PAGE).

\section{Statistical methods}

Frequencies of monoclonal IgG1 and $\lambda$-type IgG were compared to those in a published series of MGUS using Fisher's exact test. Electrophoretic mobilities were compared using MannWhitney-Wilcoxon's test. Differences with a $\mathrm{p}$ value $<0.05$ were considered significant. Computations were performed using R software.

\section{RESULTS}

Patients were aged 29 - 75 years at the time of the study (mean: 61.2 \pm 16.8 years) with a sex ratio of 1 (Table 1). Three patients presented with DNS and the remaining 9 had non-severe forms of SME.

All 12 monoclonal Ig from the SME patients were of IgG1 subclass (Table 1 and Figure 1B), including 7 with a lambda and 5 with a kappa light chain. The IgG1 restriction was significant as compared with the occurrence of IgG1 in the largest published series of MGUS (155/241 $(63 \%) ; p=0.009)$ [10], while the predominance of lambda light chain isotype in SME (7/12, $58 \%$ ) was not statistically significant as compared with the same series of MGUS (89/241, $37 \%)(\mathrm{p}=0.22)$.

In SME patients, the electrophoretic migration of the monoclonal component was significantly more cationic (median [IQR]: 1.00 [0.96 - 1.03]) than the 21 MGUS that displayed a monoclonal IgG1 (median [IQR]: 0.95 [0.85-0.98]; $\mathrm{p}=0.03$; Figure 1A).

Analyses of constant domain reactivity with a panel of $\mathrm{CH} 1-, \mathrm{CH} 2-$ and $\mathrm{CH} 3$-specific monoclonal antibodies by immunoblotting led to conclude on the absence of any deletion of the heavy chain constant region in all 12 studied SME-associated monoclonal IgG1 (Figure 1B). This was confirmed by the SDS-PAGE analysis of one SME-associated monoclonal IgG1 kappa that we could purify, as it revealed normal sizes of both heavy and light chains (Figure 2).

\section{DISCUSSION}

This study demonstrates a strict IgG1 restriction of SME-associated monoclonal immunoglobulins, and it confirms that most of them have a high isoelectric point as suggested by their cationic migration on agarose zone electrophoresis.

The bias toward IgG class and lambda type light-chain in SME MG was already noted by James et al. [7] but subclasses of IgG have not been analyzed, as far as we know. The actual 
importance of the IgG1 restriction in SME should be confirmed in a larger series, but it already appears quite significant in the present study.

The cationic electrophoretic migration of SME-associated monoclonal immunoglobulins has been evoked in small series or in a single case [7,8]. To our knowledge, this is the first statistical demonstration of cationic electrophoretic migration of SME monoclonal Ig as compared with classical MGUS. We found that this electrophoretic property is independent of the IgG1 restriction of SME-associated monoclonal component.

On the other hand, we did not confirm the results from Kitamura et al. [8] suggesting a deletion of the Fd portion (most likely the $\mathrm{CH} 1$ domain) of a monoclonal $\mathrm{IgG}$ from one SME case. Indeed, all constant domains of the heavy chains were immunoreactive in our immunoblotting studies, while 1 to 3 distinct antibodies were tested for each domain. This was confirmed in one case whose monoclonal component could be purified and analyzed by SDS-PAGE, revealing normal sized heavy and light chains.

The almost constant presence of a MG in SME, isotype restriction and basic nature of the monoclonal component pinpoint the potential role of a monoclonal plasma-cell proliferation in the pathophysiology of SME. However, a direct pathogenic role of such hematologic event and the bone marrow microenvironment remains unknown. The efficacy in severe cases of new treatments targeting putative plasma cell clones with concomitant hematological and clinical response supports the hypothesis of a direct or indirect role of these cells in the SME pathogenesis $[3,5,6]$. An old study has shown that serum factor(s), but not the monoclonal immunoglobulin alone, could stimulate in vitro fibroblast proliferation [11,12]. A hypothesis that has been suggested to explain this phenomenon could be the presence of an unknown circulating cofactor that could stimulate proliferation in association with the monoclonal immunoglobulin. Biochemical changes such as glycosylation and/or modifications of the amino acid sequence of the immunoglobulin could affect its electric charge and explain the strong association between cationic migration and SME. The great efficacy of high dose intravenous immunoglobulins in SME [2,3,13] could be explained by their immunomodulatory functions, or by increased clearance of the monoclonal Ig or its complex with a co-factor. Further studies, based for example on mass spectrometry analyses of the serum secretome, as well as functional experiments using purified monoclonal $\mathrm{Ig}$ with and without other serum fractions on human in vitro fibroblast cultures, are required for better understanding the implication of these peculiar monoclonal Ig in the pathophysiology of SME. 


\section{References}

1. Lipsker D. Monoclonal gammopathy of cutaneous significance: review of a relevant concept. J Eur Acad Dermatol Venereol 2017 Jan;31(1):45-52. (PMID: 27501129)

2. Rongioletti F, Merlo G, Cinotti E, et al. Scleromyxedema: A Multicenter Study of Characteristics, Comorbidities, Course, and Therapy in 30 Patients. J Am Acad Dermatol 2013 Jul;69(1):66-72. (PMID: 23453242)

3. Mahévas T, Arnulf B, Bouaziz JD, et al. Plasma Cell-Directed Therapies in Monoclonal Gammopathy- Associated Scleromyxedema. Blood 2020 Apr 2;135(14):1101-10. (PMID: 32027747)

4. Rongioletti F, Rebora A. Updated classification of papular mucinosis, lichen myxedematosus, and scleromyxedema. J Am Acad Dermatol 2001 Feb;44(2):273-81. (PMID: 11174386)

5. Donato ML, Feasel AM, Weber DM, et al. Scleromyxedema: role of high-dose melphalan with autologous stem cell transplantation. Blood 2006 Jan 15;107(2):463-6. (PMID: 16179379)

6. Cañueto J, Labrador J, Román C, et al. The combination of bortezomib and dexamethasone is an efficient therapy for relapsed/refractory scleromyxedema: a rare disease with new clinical insights. Eur J Haematol 2012 May;88(5):450-4. (PMID: 22404151)

7. James K, Fudenberg H, Epstein WL, Shuster J. Studies on a unique diagnostic serum globulin in papular mucinosis (lichen myxedematosus), Clin Exp Immunol 1967;2:153-66. (PMID: 4166238)

8. Kitamura W, Matsuoka Y, Miyagawa S, Sakamoto K. Immunochemical analysis of the monoclonal paraprotein in scleromyxedema. J Invest Dermatol 1978 Jun;70(6):305-8. (PMID: 349088)

9. Briault S, Courtois-Capella M, Duarte F, Aucouturier P, Preud'Homme JL. Isotypy of serum monoclonal immunoglobulins in human immunodeficiency virus-infected adults. Clin Exp Immunol 1988 Nov;74(2):182-4. (PMID: 3147151)

10. Kyle RA, Therneau TM, Rajkumar SV, Larson DR, Plevak MF, Melton LJ 3rd. Longterm follow-up of 241 patients with monoclonal gammopathy of undetermined significance: the original Mayo Clinic series 25 years later. Mayo Clin Proc 2004 Jul;79(7):859-66. (PMID: 15244381)

11. Harper RA, Rispler J. Lichen myxedematosus serum stimulates human skin fibroblast proliferation. Science 1978;199(4328):545-7. (PMID: 622555) 
12. Ferrarini M, Helfrich DJ, Walker ER, Medsger TA Jr, Whiteside TL. Scleromyxedema serum increases proliferation but not the glycosaminoglycan synthesis of dermal fibroblasts. J Rheumatol 1989;16(6):837-41. (PMID: 2778769)

13. Guarneri A, Cioni M, Rongioletti F. High-dose intravenous immunoglobulin therapy for scleromyxoedema: a prospective open-label clinical trial using an objective score of clinical evaluation system. J Eur Acad Dermatol Venereol 2017 31(7):1157-60. (PMID: 28370513)

Table 1. Demographic, clinical, and biological characteristics of 12 patients with scleromyxedema

\begin{tabular}{|l|l|l|l|l|}
\hline Patient & Gender/Age & Severity & $\begin{array}{l}\text { Monoclonal } \\
\text { Ig isotype }\end{array}$ & $\begin{array}{l}\text { Electrophoretic } \\
\text { mobility (normalized } \\
\text { value) }\end{array}$ \\
\hline 1 & $\mathrm{H} / 60$ & Non severe & $\operatorname{IgG1} \lambda$ & $\begin{array}{l}\text { Medium/cathodic } \\
(0.98)\end{array}$ \\
\hline 2 & $\mathrm{~F} / 29$ & $\begin{array}{l}\text { Severe, DNS, } \\
\text { cardiomyopathy }\end{array}$ & $\operatorname{IgG1} \lambda$ & Cathodic (1.00) \\
\hline 3 & $\mathrm{H} / 75$ & $\begin{array}{l}\text { Non severe, cutis } \operatorname{laxa}- \\
\text { like eruption, MBL }\end{array}$ & $\operatorname{IgG1} \kappa$ & Cathodic (1.02) \\
\hline 4 & $\mathrm{H} / 73$ & Non severe & $\operatorname{IgG1} \lambda$ & Cathodic (1.01) \\
\hline 5 & $\mathrm{~F} / 71$ & Non severe & $\operatorname{IgG1} \lambda$ & Cathodic (1.02) \\
\hline 6 & $\mathrm{~F} / 29$ & Severe, DNS & $\operatorname{IgG1} \kappa$ & Medium (0.92) \\
\hline 7 & $\mathrm{~F} / 75$ & Non severe & $\operatorname{IgG1} \lambda$ & Cathodic (1.00) \\
\hline 8 & $\mathrm{~F} / 69$ & Non severe & $\operatorname{IgG1} \kappa$ & Cathodic (1.10) \\
\hline 9 & $\mathrm{M} / 51$ & Non severe & $\operatorname{IgG1} \lambda$ & Medium $(0.89)$ \\
\hline 10 & $\mathrm{M} / 53$ & Non severe & $\operatorname{IgG1} \kappa$ & Anodic (0.86) \\
\hline 11 & $\mathrm{M} / 55$ & Severe, recurrent DNS & $\operatorname{IgG1} \kappa$ & Cathodic (1.11) \\
\hline 12 & $\mathrm{~F} / 75$ & Non severe & $\operatorname{IgG1} \lambda$ & Cathodic (1.05) \\
\hline
\end{tabular}

DNS: dermato-neuro syndrome; Non severe disease: absence of DNS or mucinous cardiomyopathy; MBL: monoclonal B lymphocytosis; Severe disease: presence of DNS or mucinous cardiomyopathy

\section{Figure legends}


Figure 1. (A) Comparison of electrophoretic mobilities of serum monoclonal IgG from 12 patients with scleromyxedema (SME) and 21 subjects with IgG1 MGUS (*: p < 0.05). (B) Immunoblotting analysis of $\mathrm{IgG}$ subclasses, light chain type and antigenic reactivity of $\mathrm{CH} 1$, $\mathrm{CH} 2$ and $\mathrm{CH} 3$ domains of serum samples from 2 patients with SME (used antibody clones are mentioned below corresponding strips; SPE: serum protein electrophoresis).
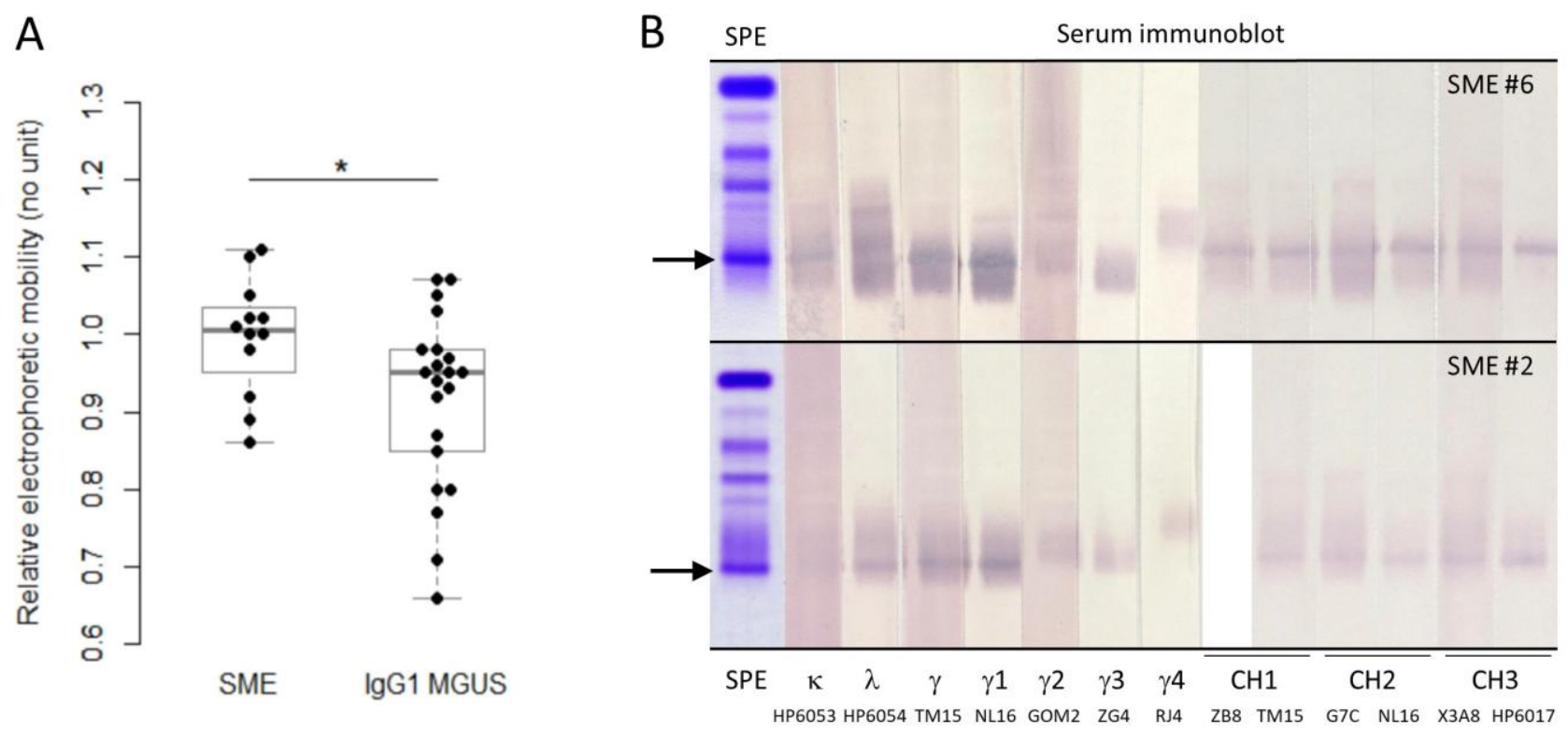

Figure 2. Apparent molecular weight of purified monoclonal IgG1 kappa from patient \#6, as compared with a purified myeloma IgG1 kappa. (A) Agarose zone electrophoresis showing serum and DEAE-purified fraction from patient \#6. (B) 12\% SDS-PAGE under reducing conditions of purified monoclonal IgG1 kappa from a scleromyxedema patient (SME \#6) and a multiple myeloma IgG1 kappa (MM control), showing normal sized heavy chain (black arrow) and light chain (white arrow).

A

B

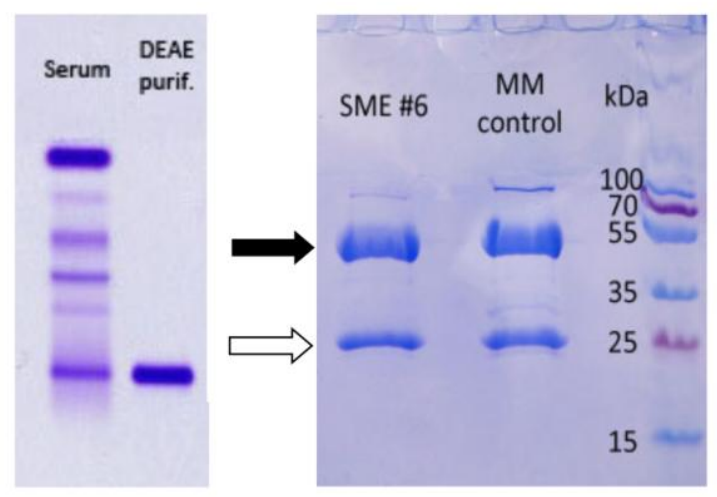

